\title{
The effect of educational intervention based on BASNEF model for reducing internet addiction among female students: a quasi-experimental study
}

\author{
Batol Gholamian ${ }^{1}$, Hossein Shahnazi ${ }^{2^{*}}$ (D) and Akbar Hassanzadeh ${ }^{3}$
}

\begin{abstract}
Background: Adolescents and students are encountered with a challenge so-called "internet Addiction". This issue affects both their physical and mental health, as well as their academic, social, and family performance. The aim of the current research is to determine the impact of educational intervention. To achieve this aim, BASNEF is utilized to reduce the excessive use of the internet by students.

Methods: This quasi-experimental study was implemented on 120 high school female students in Shahrekord (west of Iran), which were addicted to the internet. Paticipants was randomly divided into two groups of control and intervention. For data collection before and after the intervention, the standard Yang internet Addiction Questionnaire and BASNEF researcher-developed Questionnaire were used. Educational intervention for mothers was conducted in one session (as the most important subjective norm) and for students in two sessions. This method was based on BASNEF construct. Then, data were analyzed using SPSS-20 and chi-square test, MannWhitney test, independent t-test, and paired t-test.

Results: After the education intervention, the mean scores of knowledge, attitude, subjective norms, perceived behavioral control and enabling factors in the intervention group were significantly different from the control group ( $p<0.001)$. In Post-test assessment, the intervention group revealed a significant decrease, in terms of using the internet (based on the time). $(p<0.001)$.

Conclusions: The results of this study revealed that BASNEF and its related constructs was a suitable framework to design the educational interventions in order to reduce the extreme use of internet in students. Applying of this model can be a cognitive and intellectual framework that affects students' internet use behavior.
\end{abstract}

Keywords: Internet addiction, Student, Education

\section{Background}

The internet is one of the most recent human achievements, which is one of the most accessible media, and the most advanced modern communication technologies in the world. The internet provides access to a wide range of sources of information [1]. In 2000-2010, internet users worldwide grew by $44.5 \%$. Currently, the

\footnotetext{
*Correspondence: h_shahnazi@yahoo.com

${ }^{2}$ Associate Professor, Department of Health Education and Promotion, School of Health, Isfahan University of Medical Sciences, Isfahan, Iran Full list of author information is available at the end of the article
}

number of internet users is over 36 million in Iran. Internet addiction refers to excessive and uncontrolled use of the internet, which has many negative consequences for youth and adolescents' academic and social performance [2].

Internet addiction is a major and critical challenge in the adolescents worldwide [3, 4]. With overuse of the internet, they may experience educational problems, inattention, and neglect of family and friends [5].

As a result, the teenagers and youth need to be educated how to use the internet appropriately. Iranian families are moving towards single children while

(c) The Author(s). 2019 Open Access This article is distributed under the terms of the Creative Commons Attribution 4.0 International License (http://creativecommons.org/licenses/by/4.0/), which permits unrestricted use, distribution, and 
adolescents are experiencing declining social relationships and interactions. Thus, the internet is becoming the most influential factor in their lives [6].. Education can increase students' awareness of the dangers of excessive use of the internet. When students become aware of the negative effects and consequences of excessive use of the internet, they are less affected by the attraction of the internet [7].

The BASNEF is one of the models, which is utilized to study, identify, and generate new behaviors in society [8].

This model was developed by John Hubly in 1988, which its purpose was to investigate behavior and to plan for change as well as to determine those factors that affect individuals' decision making. One of the reasons to use this model in the current research is to utilize the constructs of this model as a suitable framework for designing educational interventions that influence students' addictive behavior on the internet [9].

One of the constructs of the BASNEF is to change the attitudes of students towards the extreme use of the internet. These constructs can be reinforced by appropriating group discussion, playing role and applying pattern students. Question and answer sessions enable students expressing their ideas and beliefs. Students with the help of these sessions believe that excessive use of the internet has many physical and psychological consequences [10].

Another construct is the enabling factors. Providing adequate recreational and sport facilities, creating work, and entertainment for students and occupation security can prevent internet addiction for youth. In Bangladesh, for instance, youth unemployment is high and there is no occupation security, which has led to widespread internet addiction in their community $[11,12]$.

Behavioral control is another of the BASNEF constructs that can be effective to reduce internet addiction in students. Some factors such as greater communication and social interactions, increased social acceptance of value, and self-esteem in students can reduce their internet usage. This reduction can be achieved using well-planned weekly schedules and using the internet in a controlled and planned behavior [13].

Another constructs of BASNEF is subjective norms. Some issues such as social support and mental security sense in the family and friends are to prevent an extremist accessing to the internet by students. Especially, mothers, as the main pivot of the family, are the most important subjective norm [14]. A study carried out in Jordan has shown that internet addiction is low in adolescents. The reason is that their mothers control and family supervision over the hours and cost of child internet use [15].

Given that the high prevalence of internet addiction among adolescents and students and its negative impact on both their physical and mental health, this research provides a BASNEF-based approach aimed at investigating the effect of educational intervention on reducing internet addiction in Shahrekord girls' high school students (Fig. 1).

\section{Methods}

\section{Study design and sampling}

This quasi-experimental study was implemented on 120 female high school students of Shahrekord in 2018. Initially, the sample size reached to 88 people with the power factor of $80 \%$ and standard error of $5 \%$, using the sample size calculation formula in the intervention studies. However, regarding the possibility of $10 \%$ elimination in samples, the number of samples was calculated to be 120. Sampling was carried out in a stage random sampling method, based on which from 10 girls' high schools in Shahrekord, 6 high schools were selected in

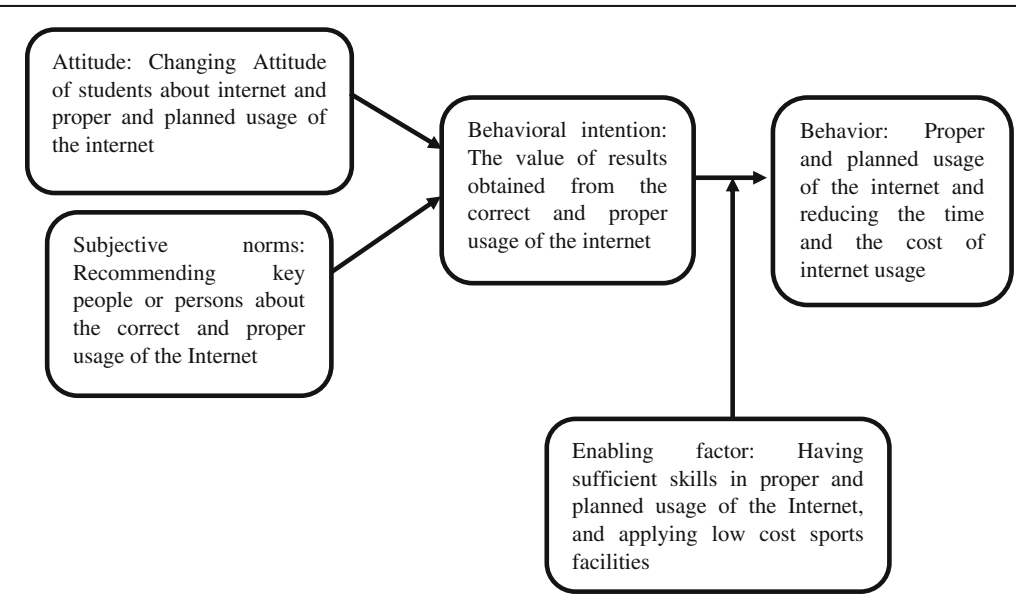

Fig. 1 The conceptual framework of this research 
the same social and economic situation. There were 712 students in these 6 high schools. Then, the standard questionnaire was distributed among students. After completing the questionnaires and analyzing their results, it was distinguished that 236 students were faced with internet addiction (That is, they used the internet for $8 \mathrm{~h}$ or more a day). Afterwards, 120 students were selected by systematic random sampling, and were assigned to control and intervention groups, using random number table. Each mentioned groups contains 60 students.

Parent and student satisfaction, being high school Student, and female gender were considered as inclusion criteria. The exclusion criteria were to be absents in educational sessions and incomplete completion of the questionnaire.

\section{Data gathering tool}

The standard Yang questionnaire was used to determine internet addiction from the students. Knowledge Questionnaire and BASNEF research questionnaire were utilized to investigate the effect of education. In the knowledge section, there were 12 multiple choice questions that gave one score to each correct answer, and zero score to each wrong answer. Therefore, the maximum score was 12 while it was zero at least.

In the BASNEF construct section, which was based on a five-point Likert scale, scored 0 to 4 points. Attitude questions were 4 questions with a maximum score of 16 and a minimum score of zero. For example: "When I feel lonely, I use the internet to talk to others".

In the Enabling Factors section, there were 4 questions with a maximum score of 16 and at least zero. For example: "Due to lack of facilities, I use the internet to fill leisure time".

The subjective norms consisted of 6 questions with following choice options: very high, high, low, very low and never. They were rated 0 to 4 based on a Likert scale. Moreover, the maximum score was 24 and the minimum score was zero. For example: "I want to hear the recommendation of my mother about the amount of use of cyber space".

Perceived behavioral control: it had 4 questions with a maximum score 16 and the score zero, at least. For example: "I can control internet usage hours during the day".

Behavioral intention: it had 4 questions with a maximum score 16 and the score zero, at least. For example: "I am going to reduce internet usage hours over the next month".

It should be noted that the questionnaires were completed by the students in both intervention and control groups before and two months after the intervention.
Finally, all questionnaire questions were calculated on the basis of 100 for ease of comparison.

\section{Validity and reliability evaluation of BASNEF questionnaire}

The validity of the questionnaire was assessed by content validity. The initial version of the questionnaire was distributed to 10 health promotion and psychology experts. According their comments, 7 equations were eliminated and 3 questions were added to the questionnaire. At the end, the validity of the questionnaire was calculated and confirmed by Content Validity Index (0.73) and Content Validity Ratio (0.85). Test- retest method was used to evaluate its reliability. In this way, the questionnaire was provided to 15 students with similar characteristics to the target group to complete it.Then, the students completed the questionnaire one week later again. Cronbach's alpha in different sections (knowledge (0.77), Attitude (0.73), subjective norms $(0.80)$ - perceived behavioral control (0.74) - enabling factors $(0.78)$ were obtained and the reliability of the questionnaire was confirmed.

\section{Intervention}

Before the educational intervention, one session was held for students and their parents about the importance of internet addiction in students and its negative consequences, and the study goals. These issues were described by the researcher. There were no reports of rejection, and all 120 were present by the end of the study. The intervention was according to BASNEF model constructs. A two-day educational session for students and one session for mothers as the most important subjective norm were conducted by a psychologist as follows:

In order to raise knowledge, a lecture about the importance of internet addiction in students and its negative consequences and effects on students' physical and mental health was presented. Then, they were asked to deliver information on internet addiction in groups of four and to provide further training sessions.

The method of group discussion and question and answer session was used to change attitudes towards internet usage. In this matter, the students posed their own questions and used a group discussion of each other's experiences with guide a teacher. The aim is to believe that internet addiction has many effects that threaten their physical and mental health. Consequently, it should be able to have a regular and controlled use of the internet.

Regarding the structure of subjective norms that included friends, parents, and especially mothers, who played a central role in the family, educational sessions were held for both mothers and students, based on 
which the role-playing method was used. To do so, one student played the role of an internet addict who used the internet in an unplanned and excessive manner. One of the mothers, as an influential subjective norm, tried to encourage the student to set up a well-regulated program of internet use. This scenario was prepared by a psychologist.

About the enable factors construct, in the case of importance of sport activities, introducing sports venues with a reasonable cost was suggested. In the case of increasing social interactions with friends and acquaintances, brainstorming method was applied. All students described their views and important comments about the best leisure alternative, which were posted on the whiteboard. It was also expected that the department of education would be required to conclude contracts with appropriate sports facilities and swimming pools at less cost.

Related to the perceived behavioral control construct, students were taught self-regulated behaviors that could be programmed and controlled using the internet. The pattern (role model) students were utilized for this purpose, which had weekly and regular use of the internet and also had low internet use costs. Then, the students were asked to design the best timetable for using the internet by giving the students papers. There was also a short video tutorial on empowering students to adjust their internet usage schedule and to reduce the cost of using the internet.

\section{Data analysis}

SPSS software (Ver20), was used to analyze the results obtained from the questionnaires. Chi-square test was also used to compare the following factors: frequency of parents' occupations, frequency of internet use between control and intervention groups. Moreover, the MannWhitney test was also used to compare the duration of internet use before and after the intervention in both groups. Furthermore, the independent $t$-test was used to compare the mean scores of knowledge, attitude, subjective norms, enabling factors and perceived behavioral control, before and after the educational intervention, in both groups. Finally, the paired t-test was also used in each group to compare the mean scores of BASNEF construct before and after the intervention.

\section{Ethical considerations}

The project has been approved by the Ethics Committee of Isfahan University of Medical Sciences under code 325739. Initially, the purpose of the study was explained to the participants. Then, the questionnaires were completed, without filling name. Moreover, participants were assured about confidentiality of information.

Table 1 Comparison of demographic characteristics of students in control and intervention groups

\begin{tabular}{|c|c|c|c|c|c|c|}
\hline \multirow[t]{2}{*}{ Variable } & & \multicolumn{2}{|c|}{ Control Group } & \multicolumn{2}{|c|}{ Intervention group } & \multirow{2}{*}{$\begin{array}{l}P_{-} \\
\text {value }\end{array}$} \\
\hline & & $\%$ & No. & $\%$ & No. & \\
\hline \multirow[t]{2}{*}{ Students' age } & 16 years old & 65 & 39 & 58.3 & 35 & 0.45 \\
\hline & 17 years old & 35 & 21 & 41.7 & 25 & \\
\hline \multirow[t]{5}{*}{ Father's occupation } & Employee & 23.3 & 14 & 30 & 18 & 0.29 \\
\hline & worker & 11.8 & 7 & 11.7 & 7 & \\
\hline & Business man & 58.3 & 35 & 50 & 30 & \\
\hline & Unemployed & 3.3 & 2 & 0 & 0 & \\
\hline & Others & 3.3 & 2 & 8.3 & 5 & \\
\hline \multirow[t]{3}{*}{ Mother's occupation } & housewife & 75 & 45 & 78.3 & 47 & 0.8 \\
\hline & Employee & 15 & 9 & 15 & 9 & \\
\hline & Others & 10 & 6 & 6.7 & 4 & \\
\hline \multirow[t]{4}{*}{ Father's level of education } & Elementary & 6.7 & 4 & 8.3 & 5 & 0.89 \\
\hline & guidance & 13.3 & 8 & 18.3 & 11 & \\
\hline & High school & 41.7 & 25 & 31.7 & 19 & \\
\hline & Academic & 38.3 & 23 & 41.7 & 25 & \\
\hline \multirow[t]{4}{*}{ Family income } & Low & 8.3 & 5 & 3.3 & 2 & 0.89 \\
\hline & medium & 20 & 12 & 26.7 & 16 & \\
\hline & Good & 63.3 & 38 & 60 & 36 & \\
\hline & Excellent & 8.3 & 5 & 10 & 6 & \\
\hline
\end{tabular}


Table 2 Frequency distribution of using internet by students in control and intervention groups

\begin{tabular}{llllll}
\hline Types of internet Use & Control Group & \multicolumn{3}{c}{ Intervention group } & $P$-value \\
\cline { 3 - 5 } & $\%$ & No. & $\%$ & No. & \\
\hline Searching on internet & 41.7 & 25 & 35 & 21 & 0.45 \\
Scientific research & 45 & 38.3 & 38.3 & 23 & 0.46 \\
Social networks & 63.3 & 58.3 & 58.3 & 35 & 0.57 \\
Spending leisure time & 63.3 & 58.3 & 58.3 & 35 & 0.26 \\
Others & 20 & 13.3 & 13.3 & 8 & 0.33 \\
\hline
\end{tabular}

\section{Results}

The results of Chi-square test indicated that the frequency distribution of mothers' occupation $(P=0.80)$ and fathers' occupation $(P=0.29)$ were not significantly different between two groups (Table 1).

Mann-Whitney test showed that there was no significant difference between two groups in terms of students' age $(P=0.45)$, Father's level of education $(P=0.89)$ and family income $(\mathrm{P}=0.89)$ (Table 1$)$.

Chi-square test revealed that there was no significant difference in frequency of internet usage between two groups $(P>0.05)$ (Table 2$)$.

Mann-Whitney test showed that there was no significant difference between two groups, in the use of internet before intervention $(P=0.68)$. Nevertheless, after the intervention, it was significantly less than the control group, in the intervention group $(P<0.001)$ (Table 3$)$.

Independent $\mathrm{t}$-test showed that the mean scores of knowledge, attitude, subjective norms, enabling factors and perceived behavioral control were not significantly different between two groups, before intervention $(P>$ 0.05). However, after applying the educational intervention, the mean scores of the mentioned constructs, in the intervention group showed a significant increase as compared to the control group $(P<0.001)$ (Table 4$)$.

Paired t-test showed that in the intervention group the mean scores of internet knowledge, subjective norms, enabling factors and perceived behavioral control related to internet addiction, after the intervention, were significantly greater than before the intervention. However, after the intervention, the mean score of positive attitude to the internet was significantly lower than before the intervention $(P<0.001)$ (Table 4$)$.

\section{Discussion}

The aim of this study was to determine the effect of educational intervention based on BASNEF constructs on decreasing internet addiction in female students.

The computational results of the study revealed that the mean score of knowledge in the intervention group was significantly increased within two months after the training. This was achieved through the use of planned lectures on the high prevalence of internet addiction among students and their effects on their physical and mental health. This result is consistent with the results of Bogale and Taddeo studies [16, 17].

Students' attitudes toward the negative consequences of excessive use of the internet and its effects on their physical and mental health were investigated through group discussions among students. After questions were asked, students participated in group discussions. Students changed over two months after the educational intervention regarding excessive and unplanned use of the internet. This suggests that the effectiveness of BASNEF model-based intervention in the area of belief and persistence is to maintain and enhance students' attitudes toward reducing internet addiction behaviors. These obtained results are consistent with a study conducted by Sarayloo [18].

In this research, the mean score of subjective norms increased within two months after the intervention. This increase was due to the presence of families, especially mothers. Their involvement in the process of changing students' behavior led to a timely use of the internet. The use of the "role-playing" approach has made students and mothers familiar with the important role of mothers in supporting adolescents and helping them plan for regular and planned usage of the internet. This result is consistent with the results of the work by Perez, Wilson and Askari [19-21].

Regarding the enabling factors mentioned in this study, a significant difference was observed in the intervention group compared to the control group, two months after the educational intervention, indicating a positive role of training in the proper use of leisure time and filling leisure time with the planning. Introducing low-cost gyms, recommending aerobic exercise, coordinating training with the most affordable swimming pools and aerobics can be identified as the most important

Table 3 frequency distribution of students' time usage of internet before and after intervention in control and intervention groups

\begin{tabular}{|c|c|c|c|c|c|c|}
\hline \multirow[t]{4}{*}{ Time usage } & \multirow[t]{2}{*}{ Score } & \multirow{2}{*}{$\begin{array}{l}\text { Control Group } \\
\%\end{array}$} & \multicolumn{3}{|c|}{ Intervention group } & \multirow[t]{2}{*}{$P$-value } \\
\hline & & & No. & $\%$ & No. & \\
\hline & Less than $8 \mathrm{~h}$ & 0 & 0 & 0 & 0 & 1 \\
\hline & $8 \mathrm{~h}$ or more & 100 & 60 & 100 & 60 & \\
\hline \multirow[t]{2}{*}{ After Intervention } & Less than $8 \mathrm{~h}$ & 27.7 & 16 & 93.3 & 56 & $0<0.001$ \\
\hline & $8 \mathrm{~h}$ or more & 73.3 & 44 & 6.7 & 4 & \\
\hline
\end{tabular}


Table 4 - Comparison of mean scores of knowledge, attitude, subjective norms, enabling factors to reduce internet addiction in control and intervention groups, before and after intervention

\begin{tabular}{|c|c|c|c|c|c|c|}
\hline & & \multicolumn{2}{|c|}{ Control Group } & \multicolumn{2}{|c|}{ Intervention group } & \multirow[t]{2}{*}{$P$-value } \\
\hline & & Mean & Standard Deviation & Mean & Standard Deviation & \\
\hline \multirow[t]{3}{*}{ Knowledge } & Before intervention & 48.56 & 23.49 & 49.16 & 20.34 & 0.88 \\
\hline & After intervention & 47.36 & 17.45 & 74.72 & 10.56 & $<0.001$ \\
\hline & $P$-value & 0.71 & & $<0.001$ & & \\
\hline \multirow[t]{3}{*}{ Attitude } & Before intervention & 67.74 & 17.77 & 69.3 & 15.19 & 0.60 \\
\hline & After intervention & 66.53 & 23.04 & 21.18 & 9.54 & $<0.001$ \\
\hline & $P$-value & 0.64 & & $<0.001$ & & \\
\hline \multirow[t]{3}{*}{ Subjective norms } & Before intervention & 41.15 & 20.62 & 40.08 & 13.43 & 0.74 \\
\hline & After intervention & 41.98 & 16.64 & 64.04 & 9.36 & $<0.001$ \\
\hline & $P$-value & 0.72 & & $<0.001$ & & \\
\hline \multirow[t]{3}{*}{ Enabling factors } & Before intervention & 28.54 & 14.44 & 28.37 & 14.21 & 0.95 \\
\hline & After intervention & 29.10 & 15.45 & 65.27 & 10.47 & $<0.001$ \\
\hline & $P$-value & 0.79 & & $<0.001$ & & \\
\hline \multirow{3}{*}{$\begin{array}{l}\text { Intention to act } \\
\text { (about ceasing the internet addiction) }\end{array}$} & Before intervention & 36.76 & 17.68 & 35.51 & 11.39 & 0.64 \\
\hline & After intervention & 37.31 & 14.88 & 84.93 & 9.23 & $<0.001$ \\
\hline & $P$-value & 0.83 & & $<0.001$ & & \\
\hline
\end{tabular}

reasons for changing "enabling factors" in intervention group students. The results of the Bantle and Green study have highlighted the importance of enabling factors to continuous behavior [22, 23].

Perceived behavioral control, in the intervention group had a significant increase compared to before the intervention. It seems that using the role model method in which the template students were used, students were asked to use the internet in a controlled and planned way as well as to use the experiences of the template students. This result is consistent with the results of Shahnazi et al's study [24].

In this paper, the effect of education on students' behavioral performance and intention on planned use of the internet was evident. In fact, students' awareness of the prevalence of internet addiction and its negative consequences increased with the introduction of question and answer sessions and group discussions, and their attitudes toward excessive use of the internet changed. On the other hand, the effect of people on the rational use of the internet increased with the presence of mothers. The above set of interventions using BASNEF constructs led to the creation of a behavioral goal and a change in internet use behavior among students.

The results in India, Kazakhstan, and Burkina Faso are also consistent with the findings of this study [25-28].

\section{Conclusion}

The aim of this study was to reduce internet addiction among students and to conduct educational intervention based on BASNEF. The results confirmed the importance of designing educational intervention using a specific model to reduce the extreme use of internet in students. As the future works, it is suggested to investigate the impact of other educational models on reducing internet addiction in students and adolescents as well as to compare its effectiveness with one of BASNEF.

\section{Limitations}

The current research was conducted on the effect of education on internet addiction reduction using BASNEF model in one of the Iranian cities. So, the results cannot be generalized to all Iranian students.

\section{Acknowledgements \\ Not applicable.}

Authors' contributions

Study concept and design: HS and BG. Drafting of the manuscript: BG. Critical revision of the manuscript for important intellectual content: HS. Statistical analysis: AH. All authors read and approved the final manuscript.

\section{Funding}

This research partially funded by Isfahan University of Medical Sciences.

\section{Availability of data and materials \\ Not applicable.}

\section{Ethics approval and consent to participate}

The project has been approved by the Ethics Committee of Isfahan University of Medical Sciences under code 325739. Initially, the purpose of the study was explained to the participants. Then, the questionnaires were completed, without filling name. Moreover, participants were assured about confidentiality of information.

Consent for publication

Not applicable. 


\section{Competing interests}

The authors declare that they have no competing interests.

\section{Author details}

'MSc in Health Education, School of Health, Isfahan University of Medical Sciences, Isfahan, Iran. ${ }^{2}$ Associate Professor, Department of Health Education and Promotion, School of Health, Isfahan University of Medical Sciences, Isfahan, Iran. Instructor, Department of Epidemiology and Biostatistics, School of Health, Isfahan University of Medical Sciences, Isfahan, Iran.

Received: 28 August 2019 Accepted: 11 December 2019 Published online: 19 December 2019

\section{References}

1. Ozturk FO, Ekinci M, Ozturk O, Canan F. The relationship of affective temperament and emotional-behavioral difficulties to internet addiction in Turkish teenagers. ISR Psychiatry. 2013:961734.

2. Scimeca G, Bruno A, Cava L, Pandolfo G, Muscatello MR, Zoccali R. The relationship between alexithymia, anxiety, depression, and internet addiction severity in a sample of Italian high school students. Scientific World Journal. 2014;12:93-7.

3. Yen JY, Ko CH, Yen CF, Wu HY, Yang MJ. The comorbid psychiatric symptoms of internet addiction: attention deficit and hyperactivity disorder (ADHD), depression, social phobia, and hostility. J Adolesc Health. 2007:41:93-8.

4. Siomos KE, Dafouli ED, Braimiotis DA, Mouzas OD, Angelopoulos NV Internet addiction among Greek adolescent students. Cyberpsychol Behav. 2008;11:653-7.

5. Lai CM, Mak KK, Watanabe H, Jeong J, Kim D, Bahar N, et al. The mediating role of Internet addiction in depression, social anxiety,equation modelling approach. Public Health. 2015;129:1224-36.

6. Kim K, Ryu E, Chon MY, Yeun EJ, Choi SY, Seo JS, et al. Internet addiction in Korean adolescents and its relation to depression and suicidal ideation: a questionnaire survey. Int J Nurs Stud. 2006;43:185-92.

7. Cao H, Sun Y, Wan Y, Hao J. Problematic internet use inchinese adolescents and its relation to psychosomatic symptoms and life satisfaction. BMC Public Health. 2011;14(11):802.

8. Lynch L, Happell B. Implementation of clinical supervision in action: part 3: the development of a model. Int J Ment Health Nurs. 2008;17:73-82.

9. Hubley J. Understanding behaviour: the key to successful health education. Trop Dr. 1988;18:134-8.

10. Zareipour M, Mahmoodi H, Valizadeh R. Impact of an Educational intervention based on basnef model on skin cancer preventive behavior of college students. Asian Pac J Cancer Prev. 2018;19:2717-22.

11. Ko CH, Liu TL, Wang PW, Chen CS, Yen CF, Yen JY. The exacerbation of depression, hostility, and social anxiety in the course of internet addiction among adolescents: a prospective study. Compr Psychiatry. 2014:55:1377-84

12. Islam MA, Hossin MZ. Prevalence and risk factors of problematic internet use and the associated psychological distress among graduate students of Bangladesh. Asian J Gambl Issues Public Health. 2016;6:11.

13. Jiang Q, Huang X, Tao R. Examining factors influencing internet addiction and adolescent risk behaviors among excessive internet users. Health Commun. 2018:33:1434-44

14. Taranto F, Goracci A, Bolognesi S, Borghini E, Fagiolini A. Internet addiction disorder in sample of 402 high school students. Psychiatr Pol. 2015;49:255-63.

15. Yousef Atoum P, Al-Hattab L. Internet addiction and its relation to psychosocial among Jordanian high basic stage students. J Psychol Behave Sci. 2015;3:96-104.

16. Bogale B, Wondafrash M, Tilahun T, Girma E. Married women's decision making power on modern contraceptive use in urban and rural southern Ethiopia. BMC Public Health. 2011;11:342.

17. Taddeo D, Egedy M, Frappier JY. Adherence to treatment in adolescents. Paediatr Child Health. 2008;13:19-24.

18. Sarayloo K, Moghadam ZB, Mansoure JM, Mostafa H, Mohsen S. The impact of an educational program based on BASNEF model on the selection of a contraceptive method in women. Iran J Nurs Midwifery Res. 2015;20:171-8.

19. Askari A, Jeihooni AK, Kashfi SM, Marzban A, Khiyali Z. The effect of educational program based on belief, attitude, subjective norm, and enabling factors model on changing the metabolic indices in elderly patients with type II diabetes. Int J Prev Med. 2018:30:74

20. Pérez-Escamilla R, Hromi-Fiedler A, Vega-López S, Bermúdez-Millán A, Segura-Pérez S. Impact of peer nutrition education on dietary behaviors and health outcomes among Latinos: a systematic literature review. J Nutr Educ Behav. 2008;40:208-25.

21. Wilson W, Pratt C. The impact of diabetes education and peer support upon weight and glycemic control of elderlypersons with noninsulin dependent diabetes mellitus (NIDDM). Am J Public Health. 1987;77:634-5.

22. Bantle JP, Wylie-Rosett J, Albright AL, Apovian CM, Clark NG, Franz MJ, et al. Nutrition recommendations and interventions for diabetes: a position statement of the American Diabetes Association. Diabetes Care. 2008;31:561-78.

23. Green LW, Glanz K, Hochbaum GM, Kok G, Kreuter MW, Lewis FM, et al. Can we build on, or must we replace, the theories and models in health education? Health Educ Res. 1994;9:397-404.

24. Shahnazi H, Bee Koon P, Abd Talib R, Lubis SH, Ganjali Dashti M, Khatooni E, et al. Can the BASNEF Model Help to Develop Self-Administered Healthy Behavior in Iranian Youth? Iran Red Crescent Med J. 2016;18:e23847.

25. Kotecha PV, Nirupam S, Karkar PD. Adolescent girls' Anaemia Control Programme, Gujarat. India Indian J Med Res. 2009;130:584-9.

26. Baizhumanova A, Nishimura A, Ito K, Sakamoto J, Karsybekova N, Tsoi I, et al. Effectiveness of communication campaign on iron deficiency anemia in Kyzyl-Orda region, Kazakhstan: A pilot study. BMC Blood Disord. 2010;10:2-8.

27. Sanou D, Turgeon-O'Brien H, Desrosiers T. Nutrition intervention and adequate hygiene practices to improve iron status of vulnerable preschool Burkinabe children. Nutrition. 2010;26:68-74

28. Senanayake HM, Premaratne SP, Palihawadana T, Wijeratne S. Simple educational intervention will improve the efficacy of routine antenatal ironsupplementation. J Obstet Gynaecol Res. 2010;36:646-50.

\section{Publisher's Note}

Springer Nature remains neutral with regard to jurisdictional claims in published maps and institutional affiliations.

Ready to submit your research? Choose BMC and benefit from:

- fast, convenient online submission

- thorough peer review by experienced researchers in your field

- rapid publication on acceptance

- support for research data, including large and complex data types

- gold Open Access which fosters wider collaboration and increased citations

- maximum visibility for your research: over $100 \mathrm{M}$ website views per year

At $\mathrm{BMC}$, research is always in progress.

Learn more biomedcentral.com/submission 